\title{
Impaired Arginine Metabolism Coupled to a Defective Redox Conduit Contributes to Low Plasma Nitric Oxide in Polycystic Ovary Syndrome
}

\author{
Meera B. Krishna ${ }^{a, b} \quad$ Annu Josepha,b Philip Litto Thomas ${ }^{a, b} \quad$ Belinda Dsilva ${ }^{a}$ \\ Sathy M. Pillaic Malini Laloraya ${ }^{a}$ \\ aFemale Reproduction and Metabolic Syndromes Laboratory, Division of Molecular Reproduction, Rajiv \\ Gandhi Centre for Biotechnology, Thycaud PO, Poojappura, Thiruvananthapuram, Kerala, ' ${ }^{\circ}$ Research \\ Scholar, Kerala University, Senate House Campus, Palayam, Thiruvananthapuram, Kerala, 'SAMAD -IVF \\ Hospitals, Pattoor, Thiruvananthapuram, Kerala, India
}

\section{Key Words}

Polycystic ovarian syndrome - Nitric oxide - Nitric Oxide Synthase • Hydrogen peroxide • Arginine bioavailability

\begin{abstract}
Background: Though oxidative stress is associated with Polycystic Ovary Syndrome (PCOS), the status of nitric oxide is still unclear. Nitric Oxide (NO) plays pivotal roles in many physiological functions which are compromised in PCOS. Our recent study reveals lowered T-regulatory cells (Tregs) in PCOS, and Treg generation is known to be regulated by NO levels. However concrete evidences are lacking on mechanisms modulating NO levels under PCOS. Methods: This is a retrospective case-control cohort study, comprised of PCOS women ( $N=29)$ and normal menstruating women as controls $(\mathrm{N}=20)$. We analysed NOx (nitrite+nitrate) and hydrogen peroxide $\left(\mathrm{H}_{2} \mathrm{O}_{2}\right)$ concentrations, transcript levels of endothelial nitric oxide synthase (eNOS)/inducible nitric oxide synthase (iNOS) and arginine modulators, hydrogen peroxide regulators in the cohort. Results: PCOS women showed reduced plasma $\mathrm{NOx}$ (nitrate+nitrite) and $\mathrm{H}_{2} \mathrm{O}_{2}$ compared to controls. We report reduction in transcript levels of iNOS/NOS2 and eNOS/NOS3 in PCOS peripheral blood. The transcripts involved in arginine bioavailability: Argininosuccinate lyase (ASL), Solute Carrier Family1, member 7 (SLC7A1) and Arginase 1 (ARG1) and Asymmetric Dimethyl Arginine (ADMA) metabolism: Protein arginine methyltransferase 1 (PRMT1) and Dimethylarginine dimethylaminohydrolase 2 (DDAH2) also showed differential expression. $\mathrm{H}_{2} \mathrm{O}_{2}$ concentration in PCOS women was also found to be reduced. The reduction can be attributed to increase in catalase levels as a consequence of the body's effort to alleviate the oxidative burden in the system. Conclusion: Our study advocates that PCOS women have lowered $\mathrm{NO}$ due to reduced iNOS/eNOS expression, low $\mathrm{H}_{2} \mathrm{O}_{2^{\prime}}$ high ADMA synthesis and reduced arginine bioavailability. An in-depth analysis of redox biology of PCOS to open up potential therapeutic strategies is highly recommended.
\end{abstract}




\section{Cellular Physiology Cell Physiol Biochem 2017;43:1880-1892 \begin{tabular}{ll|l} 
and Biochemistry & $\begin{array}{l}\text { DOI: 10.1159/000484107 } \\
\text { Published online: October 20, } 2017\end{array}$ & $\begin{array}{l}\text { O 2017 The Author(s). Published by S. Karger AG, Basel } \\
\text { www.karger.com/cpb }\end{array}$ \\
\cline { 2 - 3 }
\end{tabular} \\ Krishna et al.: Lowered Nitric Oxide in PCOS Women}

\section{Introduction}

Polycystic ovarian syndrome (PCOS) is the leading cause of onset to the metabolic syndrome in adolescent women. The classic hallmark of the disorder is a combination of hyperandrogenemia, oligo/ or anovulation and polycystic ovaries. PCOS patients are also at a high risk of comorbidities such as insulin resistance (IR), Type 2 Diabetes Mellitus, oxidative stress, inflammation, cardiovascular disorders, obesity, dyslipidemia and infertility. PCOS is ranked as the most common cause of female infertility on a global scale. Further deteriorating the scenario PCOS patients have low IVF/ICSI success rates [1] and high incidence of ovarian hyperstimulation syndrome (OHSS) [2].

The high levels of androgen and advanced glycation end products (AGEs) in PCOS women induces oxidative stress and inflammation [3]. Recent reports showed strong involvement of oxidative stress $[4,5]$ and endothelial dysfunction [6-8] in PCOS pathogenesis. Both endothelial dysfunction and oxidative stress are prognostic indicators of cardio vascular disorders, pre-eclampsia, placenta-related defects and recurrent pregnancy loss [9-12]. Endothelial function is compromised under PCOS although results on brachial artery flow-mediated dilatation (FMD) are controversial as decrease in Turkish population [13] while increase in Indian population [14] in FMD are reported. Endothelial impairment is majorly attributed to endothelial nitric oxide (NO) synthesis, its bioavailability and oxidantantioxidant mechanisms.

Nitric Oxide (NO) is a gaseous free radical molecule mediating various physiological functions like vasodilation, neuronal transmission and immune functions. It is synthesized by nitric oxide synthase (NOS) during the conversion of L-Arginine to citrulline using oxygen and NADPH as the cofactors. The enzyme nitric oxide synthase has 3 isoforms viz., the neuronal form (nNOS or NOS1), the inducible form (iNOS or NOS2) and the endothelial derived form (eNOS or NOS3). NO plays an inevitable part in various human reproductive functions which have been reviewed in great detail by Rosselli [15]. The importance of NO in male reproduction encompasses ground-breaking discovery of electrical stimulation mediated NO production and release by isolated strips of corpus cavernosum penis [16]. NO plays inevitable part in penile erection [17] and regulation of sperm motility [18] due to presence of eNOS and bNOS (nNOS) [19]. Magnitude of role of NO in female reproduction is reflected by its unequivocal involvement in follicular maturation [20], ovulation [21], decidualization [22,23], embryo implantation [24] and cervical secretion [25]. NO has been correlated with many human disorders like hypertension, diabetes, insulin resistance, obesity, stroke, neurodegenerative diseases, inflammatory disorders and infections. So, maintaining adequate amount of $\mathrm{NO}$ is a prerequisite for its proper functioning of the biological system. NO interacts with superoxide radicals $\left(\mathrm{O}_{2}{ }^{\circ}\right)$ to generate toxic peroxynitrites $\left(\mathrm{ONOO}^{-}\right)$ adding to oxygen radical burden. Superoxide dismutase (SOD), catalyses the dismutation of superoxide anion $\left(\mathrm{O}_{2}{ }^{\circ}\right)$ to produce hydrogen peroxide $\left(\mathrm{H}_{2} \mathrm{O}_{2}\right)$, and sustain adequate $\mathrm{NO}$ pool in the biological system. Substantial evidences are lacking on the stature of NO and $\mathrm{H}_{2} \mathrm{O}_{2}$ in PCOS women. PCOS women have increased oxidant xanthine oxidase (XO) activity and decreased lipid antioxidant paraoxonase 1 (PON1) activity, indicating that the patients are under high oxidative stress. Under prediabetic conditions like insulin resistance, endothelial function is found to deteriorate with decrease in NO bioavailability [26]. Contradictory reports exist about the status of NOx under PCOS. Some researchers reported decreased NO metabolites in PCOS $[27,28]$. Another noteworthy study performed in PCOS women has proved that the pregnancy rate in PCOS women can be increased through NO administration [29]. These scanty reports do not clarify the stature of $\mathrm{NO}$ and $\mathrm{H}_{2} \mathrm{O}_{2}$ in PCOS women. Therefore, exploring the status and mechanism of NO generation in PCOS is indispensable to develop novel therapeutic approaches. In-depth understanding of this aspect will contribute to improve PCOS pathology and related anomalies such as reduced uterine receptivity. 


\section{Cellular Physiology Cell Physiol Biochem 2017;43:1880-1892

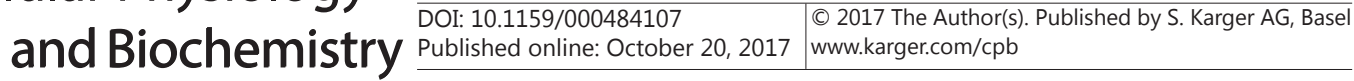 \\ Krishna et al.: Lowered Nitric Oxide in PCOS Women}

The aim of our study was to assess the status of NOS activity, factors involved in NO generation and its bioavailability modulators in peripheral blood of PCOS women. We measured the plasma levels of NOx (nitrate+nitrite), nitrite and hydrogen peroxide $\left(\mathrm{H}_{2} \mathrm{O}_{2}\right)$ in PCOS women and control subjects. We also analysed the causatory factors underlying mechanism behind the altered NO levels. To reveal the mechanism behind the NO regulation PCOS women, we conducted relative expression study of transcripts involved in $\mathrm{NO}$ and $\mathrm{H}_{2} \mathrm{O}_{2}$ pathways viz., iNOS (NOS2), eNOS (NOS3), Superoxide dismutase 2 (SOD2, enzyme for $\mathrm{H}_{2} \mathrm{O}_{2}$ synthesis), Argininosuccinate lyase (ASL, NO activator), SLC7A1 (Cationic arginine transporter), Arginase (ARG1, competitive inhibitor of nitric oxide synthase), Dimethylarginine dimethylaminohydrolase 2 (DDAH2, activator of nitric oxide synthase), and Protein arginine methyltransferase 1 (PRMT1, inhibitor of nitric oxide synthase) in peripheral blood of PCOS women.

\section{Materials and Methods}

\section{Subjects}

We conducted a retrospective case-control study including 29 PCOS patients and 20 healthy donors and collected peripheral blood on day 2-4 of follicular phase. All the patients were enrolled at SAMAD IVF clinic, Thiruvananthapuram for infertility and pregnancy related complications and were diagnosed for PCOS. The diagnosis was based on the Rotterdam European Society for Human Reproduction and Embryology (ESHRE)/American Society for Reproductive Medicine (ASRM)-sponsored PCOS Consensus Workshop Group [30]. Regular cycling women were recruited as control subjects. The study was approved by the Institute Ethical Review Board (IHEC/01/2011/08, IHEC/02/2009/14) and SAMAD ethical committee. Informed prior consent was attained from the subjects according to the declaration of Helsinki [31].

\section{Measurement of Nitric Oxide products (Nitrate plus nitrite) in plasma}

Plasma samples were centrifuged at $1500 \mathrm{rpm}$ for 20 minutes to remove protein content. The supernatant was further deproteinized by ultrafiltration through $10 \mathrm{kDa}$ cut-off filter at 4, $000 \mathrm{rpm}$ for 1 hour. The filtrate was used for further analysis. Plasma nitrate and nitrite concentrations were determined using Nitrate/Nitrite Colorimetric Assay kit (Cayman Chemicals, MI, USA) according to manufacturer's instructions. The assay involved reduction of serum nitrate to nitrite by nitrate reductase enzyme, followed by addition of Greiss reagent for converting nitrite to Azo product. Absorbance of the final product was measured at $540 \mathrm{~nm}$ using Tecan Infinite M2000 (Tecan Group, Switzerland).

\section{Measurement of Hydrogen Peroxide $\left(\mathrm{H}_{2} \mathrm{O}_{2}\right)$}

Plasma $\mathrm{H}_{2} \mathrm{O}_{2}$ was measured using the Amplex Red (Invitrogen) according to manufacturer's instructions. In the presence of horseradish peroxidise, Amplex Red reacts with $\mathrm{H}_{2} \mathrm{O}_{2}$ to form resorufin and $\mathrm{O}_{2}$. Resorufin is a stable and highly fluorescent compound whose wavelength spectra excitation/emission are 570/585 nm. $50 \mu \mathrm{L}$ of the Amplex® Red reagent/ $\mathrm{H}_{2} \mathrm{O}_{2}$ working solution was added to microplate well containing the standards, controls, and samples. The plate was incubated for 30 minutes at room temperature and the absorbance was measured in excitation range of 530-560 $\mathrm{nm}$ and fluorescence emission detection at $\sim 590$ $\mathrm{nm}$. The concentration was measured from a standard curve with $20 \mathrm{mM} \mathrm{H}_{2} \mathrm{O}_{2}$.

Total RNA extraction, First strand cDNA synthesis, Quantitative Real Time PCR

Total RNA was extracted from the whole blood samples using miRNeasy mini kit (Qiagen) according to manufacturer's protocol. The red blood cells from the peripheral blood were lysed and the leukocytes were taken for RNA extraction. The RNA samples were quantified using ND-1000 spectrophotometer (NanoDrop Technologies, Wilmington, DE). 100ng of total RNA was reverse transcribed with SuperScript ${ }^{\circledR}$ VILO $^{\text {TM }}$ cDNA Synthesis Kit and q-PCR amplification was performed with Power SYBR@Green PCR Master Mix (Life Technologies, CA). Oligonucleotide primers for transcript real time were designed by the Primer Express program. The primers used were: ARG1- F (TCC ACC CTG ATC TTG GAG TCA T), ARG1- R (GTT GTC CAT GCA AGT TTC CAC TT); ASL - F (GCC ACT GGC GTC ATC TCT AC) , ASL - R (GGA CCA GGT AAT AGG CAGG GGT); NOS2 - F (TCA CTC AGC TGT GCA TCG AC), NOS2 - R (CCT CAA GCA CAA GGT CAG GT); NOS3 - F (ATC TTC AGC CCC AAA CGG AG), NOS3 - R (CTG GAA CAT CTT CCG CCT GT ); DDAH2 - F ( CTC TGG ATC TGG CCA AAG CT), DDAH2 -R (GAC TCC TCA GGT GGC AGT TC); PRMT1 - F (TCA CAC GCT GCC ACA AGA G), PRMT1- R (ACG GTC AGG TAG TCC TCC ATG T); SLC7A1 - F (TCA CCG GCT GGA ACT TAA TC), SLC7A1 - R (CCG ATG GGT CTG CCT ATC A); SOD2-F ( GCT GCA CCA CAG CAA GCA), SOD2-R (TCG GTG ACG TTC AGG TTG TTC). The KARGER 


\section{Cellular Physiology Cell Physiol Biochem 2017;43:1880-1892

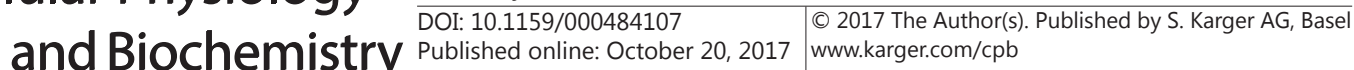 \\ Krishna et al.: Lowered Nitric Oxide in PCOS Women}

relative expression was calculated using $\triangle \Delta \mathrm{Ct}$ method with $18 \operatorname{Sr} R N A$ as the endogenous control. The run was performed on 7900HT Fast Real-Time PCR System (Applied Biosystems, CA) under standard cycling conditions.

\section{SDS- PAGE and Western Blotting}

Peripheral Blood Mononuclear Cells (PBMCs) were extracted from whole blood by standard FicollHypaque density centrifugation. Protein extract was prepared by lysing the cells in ice-cold buffer ( $50 \mathrm{mM}$ HEPES pH 7.2, 150mM NaCl, 5M EDTA, 0.5\% NP-40) containing protease inhibitor cocktail. For plasma protein extraction, the human plasma were subjected to albumin depletion and the pellets collected according to depletion of albumin component method [32]. $20 \mu \mathrm{g}$ of proteins were separated by SDS-PAGE under denaturing and reducing conditions and then proteins were transferred to PVDF membranes.

Nonspecific binding of the antibodies to the membrane was blocked by 2-hour incubation with $1 \%$ $(\mathrm{w} / \mathrm{v})$ bovine serum albumin /0.1\% (v/v) Tween 20 in Phosphate Buffered Saline (PBS). Membranes were incubated for 2 hours at room temperature with specific antibodies against SOD2, SOD3, catalase and Histone H2B [rabbit polyclonal (1:1000 dilution, Santa Cruz). Anti-rabbit IgG conjugated to horseradish peroxidase (HRP) (dilution 1:2000, Sigma) was used as the secondary antibodies to detect the signals. The signals were then measured either by ECL detection solution (GE healthcare) or by colour development using 3, 3' diaminobenzidine tetrahydrochloride dehydrate (DAB) as an electron donor, $\mathrm{H}_{2} \mathrm{O}_{2}$ as the enzyme substrate and $\mathrm{NiCl}_{2}$ as metal enhancer. A silver stained gel served as the reference control for plasma SOD3. Protein bands were visualized and images were captured on VersaDoc imaging system (BioRad).

\section{Statistical analysis}

Statistical evaluation was carried out with GraphPad Prism software. Data obtained from the study groups were compared by the parametric Student's t-test. The correlation analysis among the variables was performed by Pearson's test; a p-value $\leq 0.05$ was considered as significant. All the results are expressed as mean \pm SD.

\section{Results}

The study was conducted in a group comprising PCOS (N=29) and age-weight matched control $(\mathrm{N}=20)$ women. Other characteristics of the study group are summarised in Table1. All values are expressed as mean \pm standard deviation.

\section{PCOS women have decreased NOx /iNOS/eNOS:}

Plasma NOx end products (nitrate plus nitrite) concentration of PCOS women was significantly lower $(19.58 \mu \mathrm{M} \pm 1.165)$ compared to control $(25.81 \mu \mathrm{M} \pm 2.641)(\mathrm{t}=2.45$, $\mathrm{p}=0.018$ ) (Fig. 1a). The mean difference between the groups was $6.233 \pm 2.545$, (95\% CI 1.104 to $11.36, R^{2}=0.118$ ). Fig. $1 b$ represents the dotplot showing the nitrate plus nitrite levels in individual subjects. Nitrite levels are also reduced in PCOS women $(1.549 \pm 0.1578)$ compared to control (2.444 $\mu \mathrm{M} \pm 0.3573)$ $(\mathrm{t}=2.6, \mathrm{p}=0.0126)$, (Fig. 1c \& d) with a mean difference of 0.895 $\mu \mathrm{M} \pm 0.344,95 \% \mathrm{CI}-0.201$ to 1.59), $\mathrm{R}^{2}=0.1306$ ).

Real time PCR analysis was performed to assess the transcript expression in peripheral blood of PCOS $(\mathrm{N}=15)$ and the control $(\mathrm{N}=13)$ women. We found the enzymes involved in NO synthesis, inducible NOS (iNOS, NOS2), was

Table 1. The table represent the biochemical and physiological characteristics of PCOS ( $\mathrm{N}=22)$, Control $(\mathrm{N}=19)$ group. All values are expressed as mean \pm standard deviation. $\mathrm{P}$ value represents the significance as calculated by student's t-test between the two groups

\begin{tabular}{lccc}
\hline \multicolumn{3}{l}{ Biochemical and physiological characteristics of study group } \\
\hline Parameters & PCOS & Normal & P value \\
Age(Yr) & $28 \pm 2.52$ & $28.16 \pm 2.01$ & 0.83 \\
BMI(Kg/M $)$ & $24.96 \pm 3.22$ & $23.44 \pm 2.03$ & 0.082 \\
LH(IU/litre) & $11.5+2.67$ & $6.81 \pm 1.26$ & $2.32 \mathrm{E}-08$ \\
FSH(IU/litre) & $5.44 \pm 1.14$ & $7.12 \pm 1.40$ & 0.000134 \\
Total testosterone(ng/mL) & $46.6 \pm 17.72$ & $26.44 \pm 8.19$ & $5.13 \mathrm{E}-05$ \\
Blood Pressure, systolic & $115.91 \pm 9.08$ & $116.84 \pm 5.58$ & 0.6997 \\
Blood pressure, diastolic & $72.73 \pm 6.31$ & $74.73 \pm 5.89$ & 0.3008 \\
\hline
\end{tabular}


down regulated in patients with a fold change of -6.25 and ( $p=0.001)$ (Fig. 1e \& 1f) and endothelial NOS (eNOS, NOS3), was down regulated in patients with a fold change of -6.53 $(\mathrm{p}<0.0003)$ (Fig. 1g \& h).

Differential expression of enzymes involved in arginine bioavailability:

Arginine is the substrate for NOS during NO synthesis, thus the bioavailability of this amino acid is crucial to NOS action. On RT-PCR analysis, the transcript levels of

Fig. 1. Estimation of NO/iNOS/eNOS in PCOS women. a) Bar graph representation of concentration $(\mu \mathrm{M})$ of NO end products (Nitrite plus nitrate) in plasma of PCOS women (left) v/s control women (right). b) Dotplot representation of concentration $(\mu \mathrm{M})$ of $\mathrm{NO}$ end products (Nitrite plus nitrate) in plasma of PCOS women (left) $\mathrm{v} / \mathrm{s}$ control women (right). c) bar-graph of nitrite concentration in plasma of PCOS women (left) v/s control women (right). d) Dotplot representation of concentration $(\mu \mathrm{M})$ of nitrite in plasma of PCOS women $(\mathrm{N}=29)$ (left) v/s control women $(\mathrm{N}=19)$ (right). e) Bar graph showing real time expression analysis of iNOS (NOS2) transcript in peripheral blood of PCOS women. f) Dotplot representation of $2^{-\Delta C t}$ values of iNOS (NOS2) in PCOS women (left) v/s control women (right). g)

Bar graph showing real time expression analysis of eNOS (NOS3) transcript in peripheral blood of PCOS women. Fold change (FC), log2RQ was calculated according to $\triangle \Delta \mathrm{Ct}$ method with $18 S r R N A$ as the endogenous control. The $2^{-\Delta C t}$ values are plotted in Y axis, h) Dotplot representation of $2^{-\Delta C t}$ values of eNOS (NOS3) in PCOS women (left) v/s control women (right). Fold change (FC), log2RQ for (e) \& (g) was calculated according to $\Delta \Delta \mathrm{Ct}$ method with $18 S r R N A$ as the endogenous control. The $2^{-\Delta \mathrm{Ct}}$ values are plotted in $\mathrm{Y}$ axis. $\mathrm{P}$ value $(<0.05)$ was calculated using Student's T test on GraphPad Prism 6.0 software.

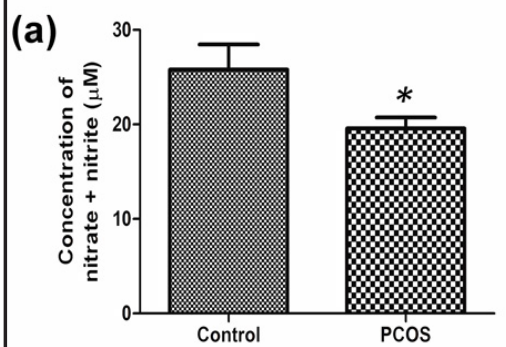

(c)

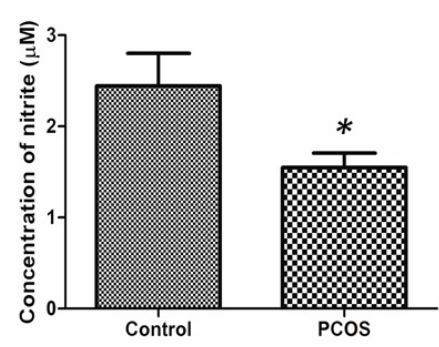

(e)

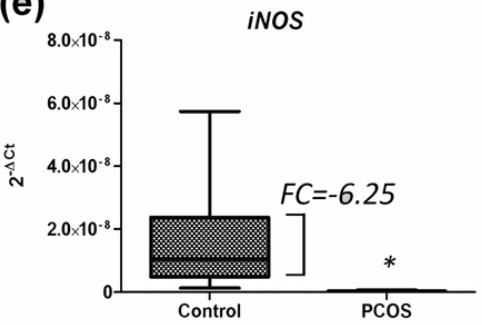

(g)

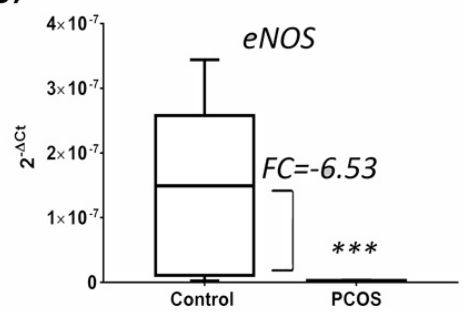

(b)

(d)

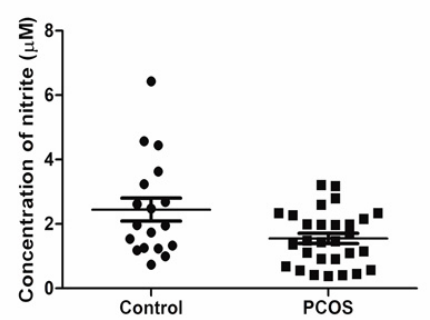

(f)

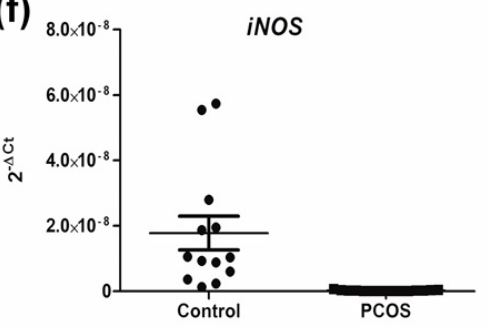

(h)

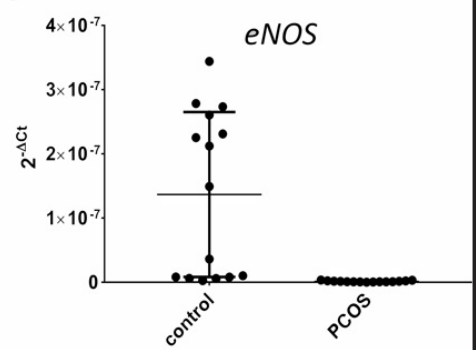


Fig. 2. Differential expression of transcripts in Arginine synthesis / transport/degradation. Bar graph representation of real time PCR analysis of a) $A S L$, c) SLC7A1 and e) $A R G 1$ in peripheral blood of Control and PCOS women. Bars represent $2^{-\Delta C t}$ of the transcripts in control (right) and PCOS (left) women. Fold change (FC), log2RQ was calculated according to $\Delta \Delta \mathrm{Ct}$ method with $18 \mathrm{SrR}$ NA as the endogenous control. The $2^{-\Delta \mathrm{Ct}}$ values are plotted in $\mathrm{Y}$ axis. $\mathrm{P}$ value $(<0.05)$ was calcula-

(a)

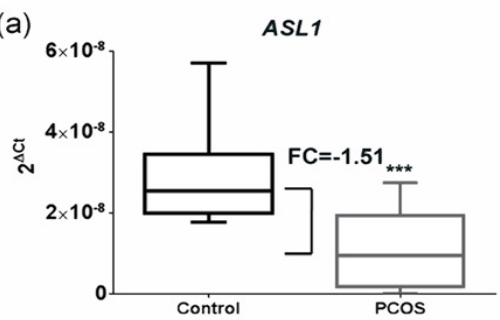

(c)

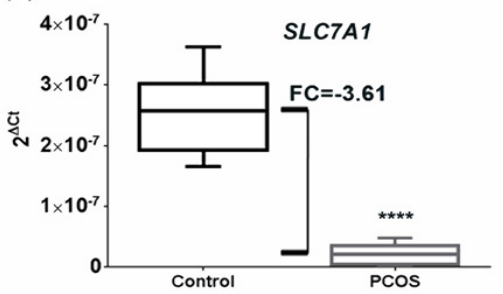

(e)

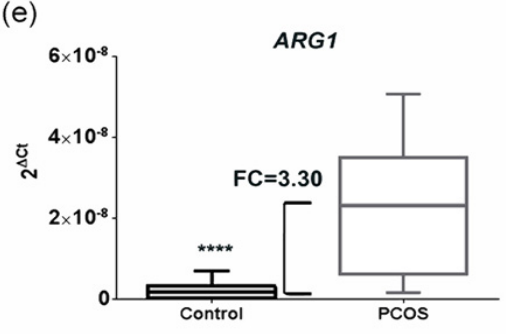

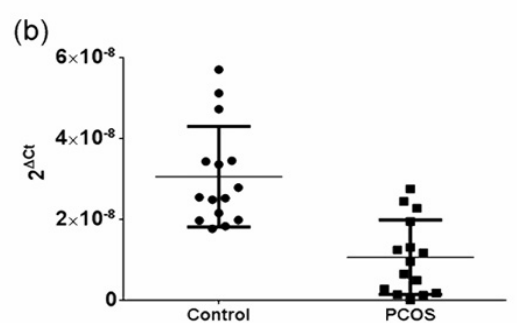

(d)

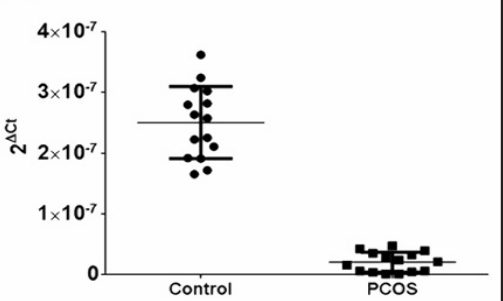

(f)

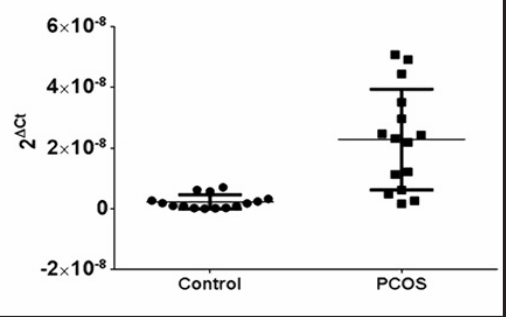
ted using Student's T test on GraphPad Prism 6.0 software. b, d and f) Dotplot representation of $2^{-\Delta c t}$ values ASL, SLC7A1 and ARG1 respectively of PCOS women (left) v/s control women (right).

Argininosuccinate lyase $(A S L)$, the enzyme involved in breakdown of arginosuccinate to arginine, showed a significant decrease with a fold change of $-1.514(\mathrm{p}<0.0002)$ (Fig. 2a). Patient variation is represented as a dotplot in Fig. 2b. Cationic arginine is transported via its transporter gene called solute carrier family 7 (cationic amino acid transporter, $\mathrm{y}+$ system), member 1 (SLC7A1). Thus, this would be important in the bioavailability of arginine for NOS action. Our results revealed a reduction of SLC7A1 levels in PCOS patients with a fold change of $-3.608(p<0.0001)$ ( Fig. 2c). Subject wise individual copy numbers are represented in Fig. 2d. The arginine degrading enzyme, Arginase 1 (ARG1) was seen to be significantly upregulated in PCOS patients with a fold change of $3.30(\mathrm{p}<0.0001)$ (Fig. 2 e \& f). The fold change was expressed as $\log 2 \mathrm{RQ}$ and the $\mathrm{p}$ values of $<0.05$ were considered to be significant.

ADMA biosynthesis regulators exhibit aberrant expression:

NOS activity is known to be regulated by Asymmetric dimethylarginine (ADMA), a competitive inhibitor of NOS. Therefore, we analysed the expression levels of transcripts involved in ADMA biosynthesis and degradation. Our results showed an increase in Protein arginine methyltransferase 1 (PRMT1) involved in ADMA biosynthesis with a fold change of 5.916 (p<0.0001) (Fig. 3 a \& b). Dimethylarginine dimethylaminohydrolase 2 (DDAH2), the enzyme which degrades methylarginines (especially ADMA and NG-monomethyl-Larginine), was significantly down regulated in our real-time expression analysis with a fold change of $-2.143(\mathrm{p}<0.001)$ (Fig. $3 \mathrm{c} \& \mathrm{~d}$ ) contributing to reduced degradation of ADMA. The fold change was expressed as log2RQ and the $\mathrm{P}$ values of $<0.05$ were considered to be significant. 


\section{Cellular Physiology Cell Physiol Biochem 2017;43:1880-1892

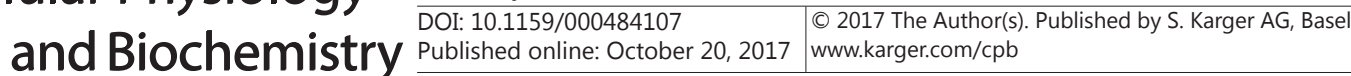

Fig. 3. Differential expression of transcripts in ADMA biosynthesis/degradation. Bar graph representation of real time PCR analysis of a) PRMT1 and c) $D D A H 2$ in peripheral blood of Control and PCOS women. Bars represent $2^{-\Delta \mathrm{Ct}}$ of the transcripts in control (right) and PCOS (left) women. Fold change (FC), log2RQ was calculated according to $\Delta \Delta \mathrm{Ct}$ method with $18 S r R N A$ as the endogenous control. The $2^{-\Delta \mathrm{Ct}}$ values are plotted in Y axis. $P$ value $(<0.05)$ was calculated using Student's T test on GraphPad Prism 6.0 software. b) and d) Dotplot representation of $2^{-\Delta \mathrm{Ct}}$ values PRMT1 and DDAH2 respectively of PCOS women (left) v/s control women (right).
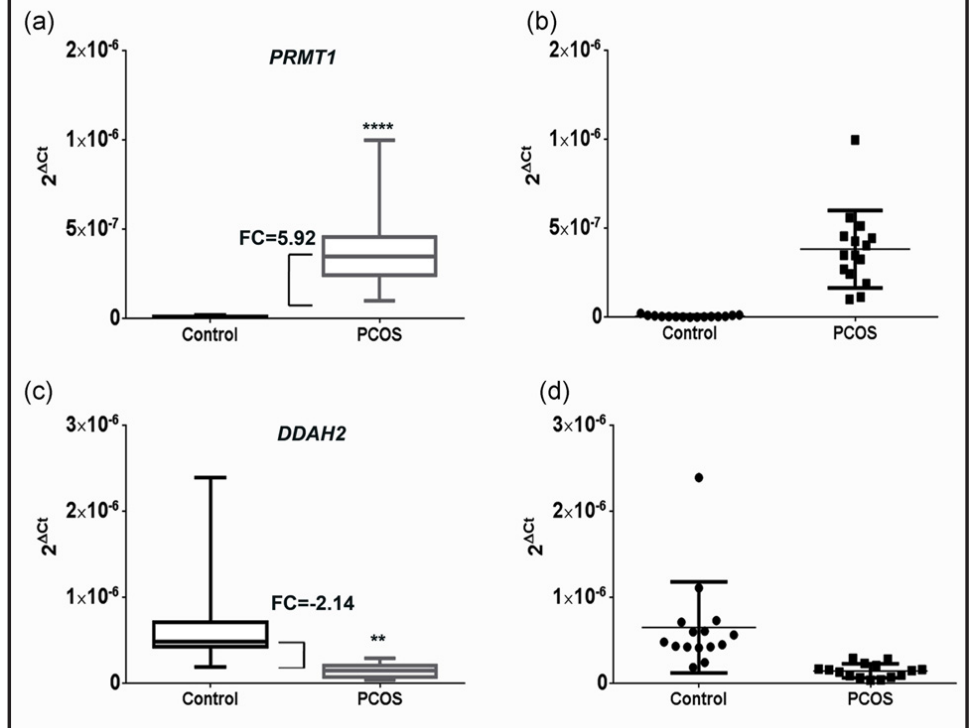
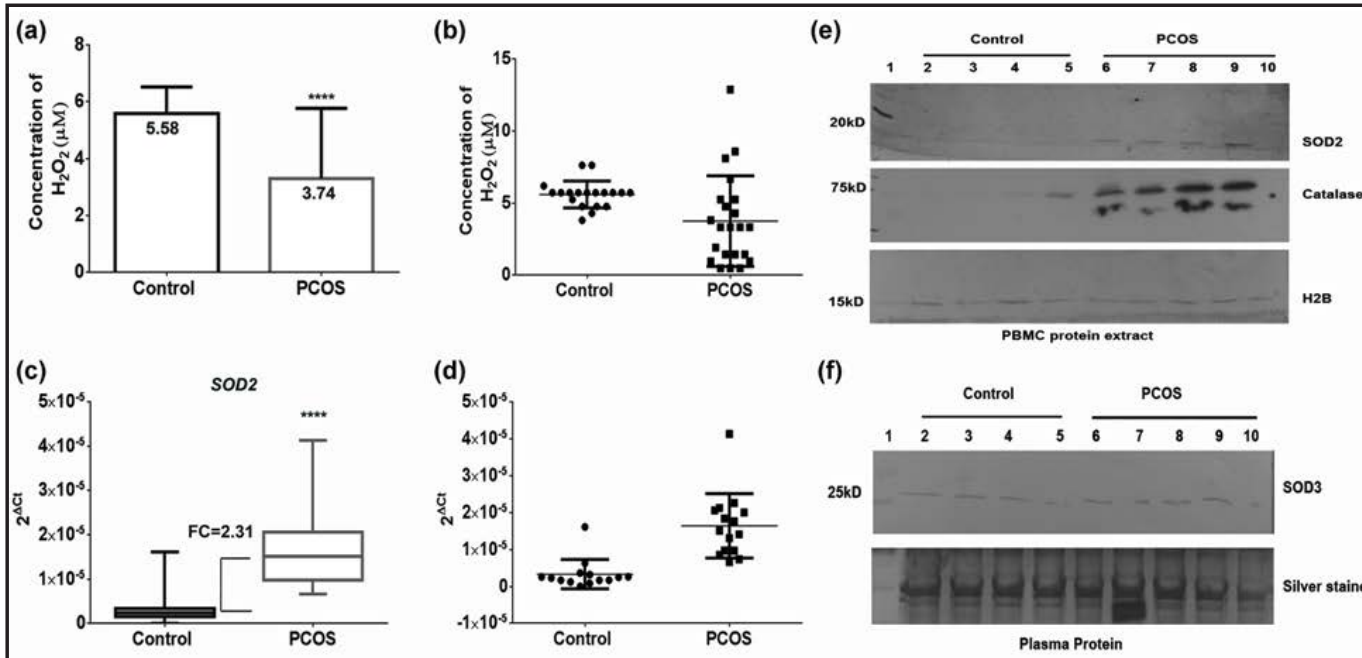

(f)

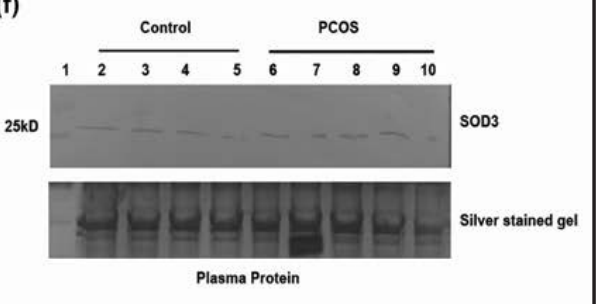

Fig. 4. Estimation of $\mathrm{H}_{2} \mathrm{O}_{2} / \mathrm{SOD} 2 / 3$ \& catalase in PCOS women. a) Bar graph representation of concentration $(\mu \mathrm{M})$ of $\mathrm{H}_{2} \mathrm{O}_{2}$ in plasma of PCOS women (left) v/s control women (right). b) Dotplot representation of concentration $(\mu \mathrm{M})$ of $\mathrm{H}_{2} \mathrm{O}_{2}$ in plasma of PCOS women (left) v/s control women (right). The estimation was performed with Amplex Red reagent and standard curve was generated using $20 \mathrm{nM}_{2} \mathrm{O}_{2}$. P value was calculated using Student's T test on GraphPad Prism 6.0. c) Bar graph representation of real time PCR analysis of SOD2 in peripheral blood of Control and PCOS women. Bars represent $2^{-\triangle \mathrm{Ct}}$ of the transcripts in control (right) and PCOS (left) women. Fold change (FC), log2RQ was calculated according to $\Delta \Delta \mathrm{Ct}$ method with 18SrRNA as the endogenous control. The $2^{-\Delta C t}$ values are plotted in Y axis. P value $(<0.05)$ was calculated using Student's T test on GraphPad Prism 6.0 software. d) Dotplot representation of 2-Act values SOD2 of PCOS women (left) v/s control women (right). e) Total PBMC extract of control (Lanes 2-5) and PCOS (Lanes 6-10) subjects were run on a single gel for direct comparison by western blotting analysis and developed against SOD2 (sc-30080, Santacruz) and Catalase (sc-50508, Santacruz). Histone H2B (sc-8651, Santacruz) was used as the endogenous control for comparison. f) Plasma proteins of control (Lanes 2-5) and PCOS (Lanes 6-10) subjects were developed against SOD3 (sc-67089, Santacruz) and Catalase (sc-50508, Santacruz). A silver stained gel was used as endogenous control. 
Impaired $\mathrm{H}_{2} \mathrm{O}_{2}$ levels characterize PCOS patients:

Our data indicated that the level of $\mathrm{H}_{2} \mathrm{O}_{2}$ in plasma of PCOS women $(3.74 \pm 3.14 \mu \mathrm{M})$ was significantly reduced in comparison with the controls $(5.588 \pm 0.94 \mu \mathrm{M}),(t=2.462$, $\mathrm{p}=0.0184)$. The mean difference between the groups was $-1.844 \pm 0.7492$ (95\% CI- -3.360 to $-0.3289, \mathrm{R}^{2}=0.1345$ ) (Fig. 4 a \& b). Since $\mathrm{H}_{2} \mathrm{O}_{2}$ is the product of SOD, we analysed the transcript and protein expression of SOD2 in whole blood. Surprisingly, our results reveal a significant $(\mathrm{p}<0.05)$ upregulation of SOD2 in PCOS women with a fold change $(\log 2 \mathrm{RQ})$ of $2.31(\mathrm{p}<0.0001)$ when compared to control women (Fig. $4 \mathrm{c} \& \mathrm{~d}$ ). The increased expression of SOD2 in whole blood of PCOS women was consistent in the protein level also (Fig. 4e). In addition, our results on differential expression of SOD3, the extracellular SOD (ecSOD) which is responsible for $\mathrm{H}_{2} \mathrm{O}_{2}$ generation in plasma, revealed mildly higher expression in PCOS (Fig. 4f). Interestingly, the protein expression of catalase, the enzyme breaking down $\mathrm{H}_{2} \mathrm{O}_{2}$ was found to be substantially increased in peripheral blood of PCOS women (Fig. 4e) thereby explaining the lowered $\mathrm{H}_{2} \mathrm{O}_{2}$ status in PCOS women.

\section{Discussion}

Reactive oxygen species mediate many functions in reproduction and are implicated in infertility, recurrent abortion, pre-eclampsia, CVDs and PCOS [33]. In the present study we focused our efforts in deciphering the regulators of NO synthesis in PCOS women. We found a significant reduction in circulating level of NO end product (NOx) in PCOS women compared to controls. Previous studies have reported reduction in NO in Turkish population [27] while Gao et al. [34] showed increased levels of NO in non-obese Chinese PCOS women. Meanwhile a couple of other studies reported no significant difference in NO levels among PCOS patients and controls $[35,36]$. Further insights on NO levels can be achieved by assessing the mechanism which maintain circulating NOx homeostasis in PCOS women. Decreased expression of eNOS and iNOS can be an explanation for our observed reduction in NOx metabolites in PCOS women. Earlier reports had shown that iNOS derived NO regulates mouse oocyte maturation [37] as well as NO-Treg generation [38]. We have recently reported lowered Tregs in PCOS [39] and thus our observed low iNOS expression assumes larger significance as it would add to the burden of reduced FOXP3 expression further compromising Treg generation. eNOS expression has been shown in PBMC especially in neutrophils and monocytes [40,41]. Decreased expression of eNOS can further augment the NOx deficiency due to reduced iNOS in PCOS women. Increased expression of eNOS and iNOS is required for tissue remodelling, vasoregulation and immunesupression at the time of embryo implantation and marks a key factor for a successful pregnancy [42]. Therefore, our observed low NO in PCOS would be one of the causative factors compromising fertility in PCOS women.

In addition, NO synthesis necessitates uptake of the semi-essential, cationic amino acid L-arginine, hence serving as the key substrate level the regulation point. A pilot study involving metabolic profiling had shown that levels of both arginine [43] and citrulline are significantly reduced in PCOS women. The modulation of arginine bioavailability can occur at degradation, synthesis or transport level. The over expression of Arginase 1 (ARG1), the enzyme involved in arginine breakdown to ornithine and urea can deplete the substrate pool of L-arginine that would otherwise be available to NO synthase. Thus, the increased Arginase 1 observed in PCOS patients would limit arginine bioavailability for NOS action. On the contrary, Argininosuccinate lyase (ASL) can replenish the arginine substrate pool by reversibly breaking down argininosuccinate (ASA). Loss of ASL would lead to abridged NO synthesis, due to both impaired endogenous arginine synthesis and an inability to employ extracellular arginine for NO production [44]. Consequently, the decrease in ASL transcript 
in our study group can also add to the plunge of NO. Transport of L-arginine mediated by the activity of high-affinity cationic amino acid transporters 1 (hCAT-1) and 2 (hCAT-2). hCAT-1 is encoded by SLC7A1 gene whose promoter activity is highly enhanced by insulin [45]. The insulin insensitivity in PCOS women can be a strong ground for decreasing SLC7A1 transcript and arginine transport in PCOS women in our study. Since NO is a short lived free radical, usually therapeutic interventions for NO deficiency is achieved by L -arginine supplementation. Long-standing L-arginine therapy was reported to improve gonadal dyfunction under PCOS [46]. The aberrant arginine pathway hence implicated by our study in PCOS women can have significant clinical implications.

Asymmetrical dimethylarginine (ADMA), guanidine substituted substrate analogue of L arginine impairs NO synthesis by competing for endogenous nitric oxide synthase. ADMA belongs to group of methylarginines derived from the degradation of methylated proteins. In addition to higher symmetric dimethylarginine (SDMA) [47], ADMA levels have been shown to be significantly higher in PCOS women [48-51]. DDAH2 enzyme plays a pivotal role in clearance of ADMA in endothelial cells [4]. The reduction of DDAH2 in our study can create alterations in DDAH/ADMA/NOS/NO pathway, accumulating ADMA and in this manner inhibiting NOS and NO synthesis. Higher expression of PRMT1, (enzyme deriving methyl group from S-adenosylmethionine for ADMA synthesis) also can direct the metabolic pathway to enhanced synthesis of large amounts of ADMA.

Another very important finding from the study was the observed low circulating levels of $\mathrm{H}_{2} \mathrm{O}_{2}$ in PCOS women. Short exposure of $\mathrm{H}_{2} \mathrm{O}_{2}$ on endothelial cells can enhance NO synthesis whereas excess exposure to $\mathrm{H}_{2} \mathrm{O}_{2}$ reduces $\mathrm{NO}^{\bullet}$ Bioavailability [52]. Our data connoted that $\mathrm{H}_{2} \mathrm{O}_{2}$ levels in PCOS could play a role in regulating NO synthesis. $\mathrm{H}_{2} \mathrm{O}_{2}$ is converted to water by glutathione peroxidase (GPX) or catalase. The reduced $\mathrm{H}_{2} \mathrm{O}_{2}$ levels in PCOS reported here could be an impact of efficient clearance mechanism of $\mathrm{H}_{2} \mathrm{O}_{2}$ by elevated catalase expression. This specific result is corroborated by reports of Bausenwein et al., showing increased activity of catalase in follicular fluid of PCOS women [53].

Fig. 5. Cartoon depicting the differential Nitric Oxide metabolic pathway in PCOS. Under PCOS condition, the level of NO. is reduced. The reduction in NO can be attributed to two factors. 1. Arginine bioavailability: Arginine bioavailability may be limited as the transcripts involved in arginine synthesis (ASL) and transport (SLC7A1) are under expressed while degradation (ARG1) is over expressed. 2. Nitric oxide synthase (NOS) concentration/activity:

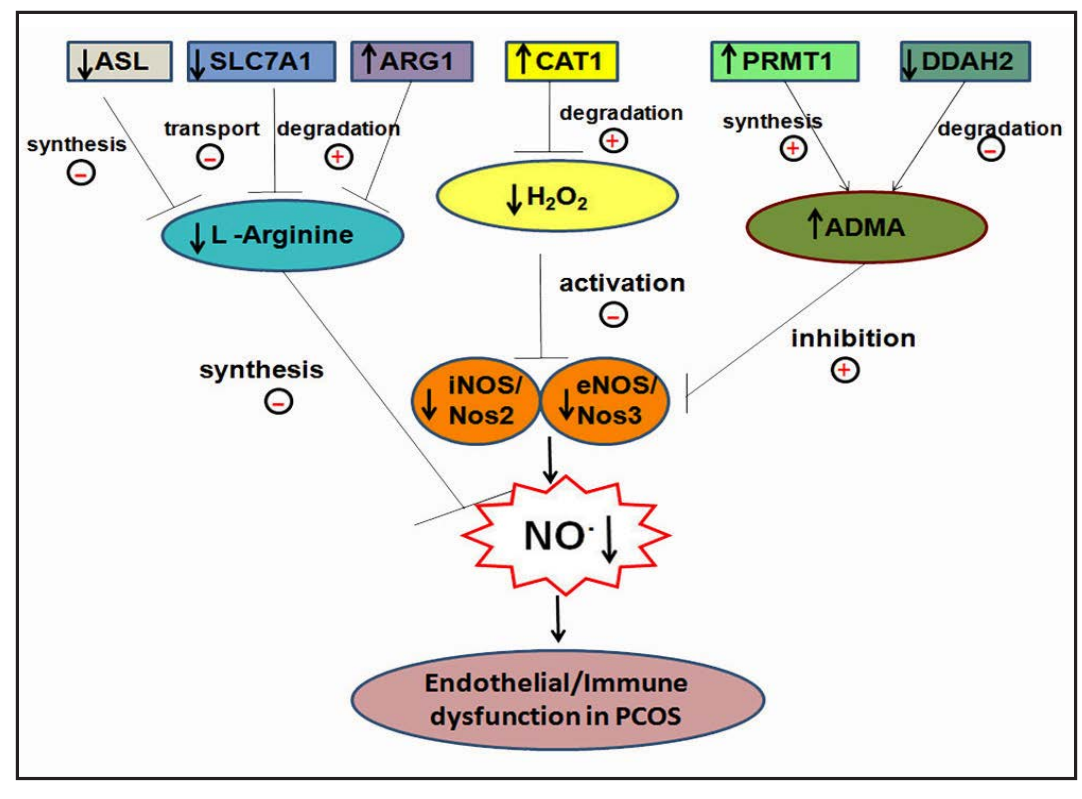
Transcripts of NOS2 and

NOS3 are under expressed in PCOS. The activity of NOS may be inhibited by low levels of hydrogen peroxide (attributed to high catalase levels and high ADMA (resulting from over expression of PRMT1 involved in ADMA synthesis and under expression of DDAH1 involved in ADMA degradation). The low NO can lead to compromised endothelial and immune functions in PCOS patients.

\section{KARGER}


Our microarray expression profiling (data not shown) and real time PCR experiment in peripheral blood of PCOS women has revealed an increased expression of SOD2, the principal enzyme involved in $\mathrm{H}_{2} \mathrm{O}_{2}$ synthesis. SOD activity in PCOS serum has been reported with contradicting results $[5,12,54-56]$. The higher expression of SOD implies higher antioxidant activity in PCOS to combat higher intrinsic reactive oxygen species induced oxidative load [57]. Thus, our results showing higher expression of SOD2 as well as SOD3 expression represent the body's local defence mechanism to alleviate higher levels of ROS produced in PCOS. We presume that the increased expression of antioxidant enzymes as SOD2/3 and catalase are responsible for the reduction of $\mathrm{H}_{2} \mathrm{O}_{2}$ under PCOS.

The reduction of NOx in peripheral blood can have extensive implications in PCOS. Niedbala et al. have reported $\mathrm{NO}^{*}$ to induce $\mathrm{CD}^{+} \mathrm{CD}_{2} 5^{+} \mathrm{Foxp} 3^{-}$regulatory $\mathrm{T}$ cells $\left(\mathrm{NO}^{*}\right.$ Tregs) with suppressive properties in peripheral blood [38]. In our previous study we showed that peripheral pool of PCOS women contained low T-regulatory cells (Tregs) [39]. This is a strong implication that lowered NOS activity on account of decreased iNOS/eNOS expression in PBMC of PCOS patients contributes to decreased NO^-Tregs and exacerbates Treg depletion due to lowered FOXP3. Low NOx lead to compromised uterine receptivity in PCOS women and this is substantiated by reports of increased uterine iNOS at the time of implantation [58]. High levels of iNOS at the time of implantation can be a strong indication of higher number of Tregs at implantation for enabling immune tolerance. Our observations and implications are represented in Fig. 5. NO is an important factor determining IVF success rates [59]. The report is of utmost importance as a recent study has reported that the IVF success rates in obese PCOS women is low on account of higher miscarriage risk [1]. Hence, NOx insufficiency in PCOS women has to be addressed at an early level. Therapeutic interventions can be achieved through L-arginine supplementation, since NO is short lived. Contemporary and alternative approach would suggest PCOS women to incorporate L-arginine rich foods (peanuts and walnuts, meats, seafood and legumes such as soybean and chickpeas) in their diet.

\section{Acknowledgements}

This work was supported from intramural core grants from Department of Biotechnology (DBT), India to Dr. Malini Laloraya. Council for Scientific and Industrial Research fellowships supported Meera Krishna B. (10.2(5)/2007(ii).E.U.II) and Annu Joseph (09/716(0130)/2010-EMR-I) while University Grants Commission supported Philip Litto Thomas (FIP/12 ${ }^{\text {th }}$ Plan/KLMG026 TF-14). The support by staff at SAMAD IVF Hospital in patient recruitment and patient data management is also acknowledged. The authors acknowledge RGCB for core facilities.

\section{Disclosure Statement}

The authors declare no competing financial interests.

\section{References}

1 Cui N, Wang H, Wang W, Zhang J, Xu Y, Jiang L, Yang A, Hao G: Impact of Body Mass Index on Outcomes of In vitro Fertilization/Intracytoplasmic Sperm Injection Among Polycystic Ovarian Syndrome Patients. Cell Physiol Biochem 2016;39:1723-1734.

2 Zhao C, Liu X, Shi Z, Zhang J, Zhang J, Jia X, Ling X: Role of serum miRNAs in the prediction of ovarian hyperstimulation syndrome in polycystic ovarian syndrome patients. Cell Physiol Biochem 2015;35:10861094. 


\section{Cellular Physiology Cell Physiol Biochem 2017;43:1880-1892 \begin{tabular}{ll|l} 
and Biochemistry Published onlIne: October 20, 2017 & $\begin{array}{l}\text { (c) } 2017 \text { The Author(s). Published by S. Karger AG, Basel } \\
\text { www.karger.com/cpb }\end{array}$ \\
\hline
\end{tabular} \\ Krishna et al.: Lowered Nitric Oxide in PCOS Women}

3 Palioura E, Palimeri S, Piperi C, Sakellariou S, Kandaraki E, Sergentanis T, Levidou G, Agrogiannis G, Papalois A, Korkolopoulou P, Diamanti-Kandarakis E, Papavassiliou AG: Impact of androgen and dietary advanced glycation end products on female rat liver. Cell Physiol Biochem 2015;37:1134-1146.

-4 Liu LH, Guo Z, Feng M, Wu ZZ, He ZM, Xiong Y: Protection of DDAH2 Overexpression Against HomocysteineInduced Impairments of DDAH/ADMA/NOS/NO Pathway in Endothelial Cells. Cell Physiol Biochem 2012;30:1413-1422.

5 Sabuncu T, Vural H, Harma M, Harma M: Oxidative stress in polycystic ovary syndrome and its contribution to the risk of cardiovascular disease. Clin Biochem 2001;34:407-413.

-6 Carmina E, Orio F, Palomba S, Longo RA, Cascella T, Colao A, Lombardi G, Rini GB, Lobo RA: Endothelial dysfunction in PCOS: role of obesity and adipose hormones. Am J Med 2006;119:356-3e1.

7 Lakhani K, Leonard A, Seifalian AM, Hardiman P: Microvascular dysfunction in women with polycystic ovary syndrome. Hum Reprod 2005;20:3219-3224.

8 Paradisi G, Steinberg HO, Hempfling A, Cronin J, Hook G, Shepard MK, Baron AD: Polycystic ovary syndrome is associated with endothelial dysfunction. Circulation 2001;103:1410-1415.

-9 Burton GJ, Jauniaux E: Placental oxidative stress: from miscarriage to preeclampsia. J Soc Gynecol Investig 2004;11:342-352.

10 Germain AM, Romanik MC, Guerra I, Solari S, Reyes MaS, Johnson RJ, Price K, Karumanchi SA, Vald+าS G: Endothelial Dysfunction A Link Among Preeclampsia, Recurrent Pregnancy Loss, and Future Cardiovascular Events? Hypertension 2007;49:90-95.

-11 Jauniaux E, Watson AL, Hempstock J, Bao YP, Skepper JN, Burton GJ: Onset of maternal arterial blood flow and placental oxidative stress: a possible factor in human early pregnancy failure. Am J Pathol 2000;157:2111-2122.

12 Kuscu NK, Var A: Oxidative stress but not endothelial dysfunction exists in non-obese, young group of patients with polycystic ovary syndrome. Acta Obstet Gynecol Scand 2009;88:612-617.

13 Soyman Z, Noyan V, Tulmac M, Yucel A, Sagsoz N, Bayrak T, Bayrak A, Cakir E: Serum paraoxonase 1 activity, asymmetric dimethylarginine levels, and brachial artery flow-mediated dilatation in women with polycystic ovary syndrome. Fertil Steril 2011;95:1067-1072.

14 Karoli R, Fatima J, Siddiqi Z, Vatsal P, Sultania AR, Maini S: Study of early atherosclerotic markers in women with polycystic ovary syndrome. Indian J Endocrinol Metab 2012;16:1004-1008.

15 Rosselli M, Keller PJ, Dubey RK: Role of nitric oxide in the biology, physiology and pathophysiology of reproduction. Hum Reprod Update 1998;4:3-24.

16 Ignarro LJ, Bush PA, Buga GM, Wood KS, Fukuto JM, Rajfer J: Nitric oxide and cyclic GMP formation upon electrical field stimulation cause relaxation of corpus cavernosum smooth muscle. Biochem Biophys Res Commun 1990;170:843-850.

17 Holmquist F, Stief CG, Jonas U, Andersson KE: Effects of the nitric oxide synthase inhibitor NG-nitroL-arginine on the erectile response to cavernous nerve stimulation in the rabbit. Acta Physiol Scand 1991;143:299-304.

-18 Hellstrom WJ, Bell M, Wang R, Sikka SC: Effect of sodium nitroprusside on sperm motility, viability, and lipid peroxidation. Fertil Steril 1994;61:1117-1122.

19 Lewis SE, Donnelly ET, Sterling ES, Kennedy MS, Thompson W, Chakravarthy U: Nitric oxide synthase and nitrite production in human spermatozoa: evidence that endogenous nitric oxide is beneficial to sperm motility. Mol Hum Reprod 1996;2:873-878.

20 Rosselli M, Imthurm B, Macas E, Keller PJ, Dubey RK: Circulating nitrite/nitrate levels increase with follicular development: indirect evidence for estradiol mediated NO release. Biochem Biophys Res Commun 1994;202:1543-1552.

21 Shukovski L, Tsafriri A: The involvement of nitric oxide in the ovulatory process in the rat. Endocrinology 1994;135:2287-2290.

22 Chwalisz K, Winterhager E, Thienel T, Garfield RE: Synergistic role of nitric oxide and progesterone during the establishment of pregnancy in the rat. Hum Reprod 1999;14:542-552.

23 Spencer F, Chi L, Zhu MX: Antiproliferative effects of inducible nitric oxide synthase inhibition on decidualization in pseudopregnant rats. Proc Soc Exp Biol Med 1998;218:45-50.

-24 Ota H, Igarashi S, Oyama N, Suzuki Y, Tanaka T: Optimal levels of nitric oxide are crucial for implantation in mice. Reprod Fertil Dev 1999;11:183-188. 


\section{Cellular Physiology Cell Physiol Biochem 2017;43:1880-1892 \begin{tabular}{ll|l} 
DOI: 10.1159/000484107 & $\begin{array}{l}\text { O 2017 The Author(s). Published by S. Karger AG, Basel } \\
\text { www.karger.com/cpb }\end{array}$ \\
\hline and Biochemistry Published online: October 20, 201 &
\end{tabular}

25 Morlin B, Hammarstrom M: Nitric oxide increases endocervical secretion at the ovulatory phase in the female. Acta Obstet Gynecol Scand 2005;84:883-886.

-26 Sydow K, Mondon CE, Cooke JP: Insulin resistance: potential role of the endogenous nitric oxide synthase inhibitor ADMA. Vasc Med 2005;10:S35-S43.

-27 Bayram F, Kocer D, Ozsan M, Muhtaroglu S: Evaluation of endothelial dysfunction, lipid metabolism in women with polycystic ovary syndrome: relationship of paraoxonase 1 activity, malondialdehyde levels, low-density lipoprotein subfractions, and endothelial dysfunction. Gynecol Endocrinol 2012;28:497-501.

-28 Yavuz TM, Kilic N, Bayraktar N, Guler I, Gulcan KY, Goktas T, Taner MZ, Himmetoglu MO, Yaman H, Taslipinar A: Endothelial dysfunction and insulin resistance in young women with polycystic ovarian syndrome. Turk J Med Sci 2014;44:787-791.

29 El-Berry S, Razik MA: Nitric oxide donors increases pregnancy rate in clomiphene citrate treated polycystic ovary infertile patients. Middle East Fertil Soc J 2010;15:106-109.

-30 Rotterdam ESHR, ASRM-Sponsored PCOS: Revised 2003 consensus on diagnostic criteria and long-term health risks related to polycystic ovary syndrome (PCOS). Hum Reprod 2004;19:41.

31 Rickham PP: Human Experimentation. Code of Ethics of the World Medical Association. Declaration of Helsinki. Br Med J 1964;2:177.

-32 Colantonio DA, Dunkinson C, Bovenkamp DE, Van Eyk JE: Effective removal of albumin from serum. Proteomics 2005;5:3831-3835.

-33 Agarwal A, Gupta S, Sekhon L, Shah R: Redox considerations in female reproductive function and assisted reproduction: from molecular mechanisms to health implications. Antioxid Redox Signal 2008;10:13751404.

-34 Gao H, Meng J, Xu M, Zhang S, Ghose B, Liu J, Yao P, Yan H, Wang D, Liu L: Serum Heat Shock Protein 70 Concentration in Relation to Polycystic Ovary Syndrome in a Non-Obese Chinese Population. PLoS One 2013;8:e67727.

35 Baskol G, Aygen E, Erdem F, Caniklioglu A, Narin F, Sahin Y, Kaya T: Assessment of paraoxonase 1, xanthine oxidase and glutathione peroxidase activities, nitric oxide and thiol levels in women with polycystic ovary syndrome. Acta Obstet Gynecol Scand 2012;91:326-330.

36 Willis GR, Udiawar M, Evans WD, Blundell HL, James PE, Rees DA: Detailed characterisation of circulatory nitric oxide and free radical indices--is there evidence for abnormal cardiovascular homeostasis in young women with polycystic ovary syndrome? BJOG 2014;121:1596-1603.

37 Jablonka-Shariff A, Olson LM: Nitric oxide is essential for optimal meiotic maturation of murine cumulusoocyte complexes in vitro. Mol Reprod Dev 2000;55:412-421.

-38 Niedbala W, Cai B, Liu H, Pitman N, Chang L, Liew FY: Nitric oxide induces CD4+CD25+ Foxp3 regulatory T cells from CD4+CD25 T cells via p53, IL-2, and OX40. Proc Natl Acad Sci U S A 2007;104:15478-15483.

-39 Krishna MB, Joseph A, Subramaniam AG, Gupta A, Pillai SM, Laloraya M: Reduced Tregs in peripheral blood of PCOS patients - a consequence of aberrant Il2 signaling. J Clin Endocrinol Metab 2015;100:282-292.

-40 Kumar S, Jyoti A, Keshari RS, Singh M, Barthwal MK, Dikshit M: Functional and molecular characterization of NOS isoforms in rat neutrophil precursor cells. Cytometry A 2010;77:467-477.

-41 Saluja R, Jyoti A, Chatterjee M, Habib S, Verma A, Mitra K, Barthwal MK, Bajpai VK, Dikshit M: Molecular and biochemical characterization of nitric oxide synthase isoforms and their intracellular distribution in human peripheral blood mononuclear cells. Biochim Biophys Acta 2011;1813:1700-1707.

42 Purcell TL, Given R, Chwalisz K, Garfield RE: Nitric oxide synthase distribution during implantation in the mouse. Mol Hum Reprod 1999;5:467-475.

43 Atiomo W, Daykin CA: Metabolomic biomarkers in women with polycystic ovary syndrome: a pilot study. Mol Hum Reprod 2012;18:546-553.

-44 Erez A, Nagamani SC, Shchelochkov OA, Premkumar MH, Campeau PM, Chen Y, Garg HK, Li L, Mian A, Bertin TK: Requirement of argininosuccinate lyase for systemic nitric oxide production. Nat Med 2011;17:16191626.

45 Gonzalez M, Gallardo V, Rodriguez N, Salomon C, Westermeier F, Guzman-Gutierrez E, Abarzua F, Leiva A, Casanello P, Sobrevia L: Insulin-stimulated L-arginine transport requires SLC7A1 gene expression and is associated with human umbilical vein relaxation. J Cell Physiol 2011;226:2916-2924.

-46 Masha A, Manieri C, Dinatale S, Bruno GA, Ghigo E, Martina V: Prolonged treatment with N-acetylcysteine and L-arginine restores gonadal function in patients with polycystic ovary syndrome. J Endocrinol Invest 2009;32:870-872. 


\section{Cellular Physiology Cell Physiol Biochem 2017;43:1880-1892 \begin{tabular}{l|l|l} 
DOI: 10.1159/000484107 & O 2017 The Author(s). Published by S. Karger AG, Basel \\
and Biocharger.com/cpb
\end{tabular} \\ Krishna et al.: Lowered Nitric Oxide in PCOS Women}

47 Lakhani K, Kay AR, Leiper J, Barry JA, Hardiman PJ: Symmetric dimethylarginine (SDMA) is raised in women with polycystic ovary syndrome: a pilot study. J Obstet Gynaecol 2011;31:417-419.

48 Bayrak T, Dursun P, Bayrak A, Gultekin M, Kolusari A, Cakir E, Ozyurt M, Zeyneloglu HB: Paraoxonase lactonase activity (PON-HTLase), asymmetric dimethylarginine (ADMA) and platelet activating factoracetylhydrolase (PAF-AH) activity in non-obese women with PCOS. Gynecol Endocrinol 2012;28:874-878.

-49 Choi YS, Yang HI, Cho S, Jung JA, Jeon YE, Kim HY, Seo SK, Lee BS: Serum asymmetric dimethylarginine, apelin, and tumor necrosis factor-alpha levels in non-obese women with polycystic ovary syndrome. Steroids 2012;77:1352-1358.

50 Heutling D, Schulz H, Nickel I, Kleinstein J, Kaltwasser P, Westphal S, Mittermayer F, Wolzt M, Krzyzanowska K, Randeva H, Schernthaner G, Lehnert H: Asymmetrical dimethylarginine, inflammatory and metabolic parameters in women with polycystic ovary syndrome before and after metformin treatment. J Clin Endocrinol Metab 2008;93:82-90.

-51 Rajendran S, Willoughby SR, Chan WP, Liberts EA, Heresztyn T, Saha M, Marber MS, Norman RJ, Horowitz JD: Polycystic ovary syndrome is associated with severe platelet and endothelial dysfunction in both obese and lean subjects. Atherosclerosis 2009;204:509-514.

-52 Thomas SR, Chen K, Keaney JF: Hydrogen peroxide activates endothelial nitric-oxide synthase through coordinated phosphorylation and dephosphorylation via a phosphoinositide 3-kinase-dependent signaling pathway. J Biol Chem 2002;277:6017-6024.

-53 Bausenwein J, Serke H, Eberle K, Hirrlinger J, Jogschies P, Hmeidan FA, Blumenauer V, Spanel-Borowski $\mathrm{K}$ : Elevated levels of oxidized low-density lipoprotein and of catalase activity in follicular fluid of obese women. Mol Hum Reprod 2010;16:117-124.

54 Liu J, Zhang D: [The role of oxidative stress in the pathogenesis of polycystic ovary syndrome]. Sichuan Da Xue Xue Bao Yi Xue Ban 2012;43:187-190.

-55 Macut D, Simic T, Lissounov A, Pljesa-Ercegovac M, Bozic I, Djukic T, Bjekic-Macut J, Matic M, Petakov M, Suvakov S, Damjanovic S, Savic-Radojevic A: Insulin resistance in non-obese women with polycystic ovary syndrome: relation to byproducts of oxidative stress. Exp Clin Endocrinol Diabetes 2011;119:451-455.

56 Seleem AK, El Refaeey AA, Shaalan D, Sherbiny Y, Badawy A: Superoxide dismutase in polycystic ovary syndrome patients undergoing intracytoplasmic sperm injection. J Assist Reprod Genet 2014;31:499-504.

57 Gonzalez F, Rote NS, Minium J, Kirwan JP: Reactive oxygen species-induced oxidative stress in the development of insulin resistance and hyperandrogenism in polycystic ovary syndrome. J Clin Endocrinol Metab 2006;91:336-340.

58 Saxena D, Purohit SB, Kumer GP, Laloraya M: Increased appearance of inducible nitric oxide synthase in the uterus and embryo at implantation. Nitric Oxide 2000;4:384-391.

59 Lee TH, Wu MY, Chen MJ, Chao KH, Ho HN, Yang YS: Nitric oxide is associated with poor embryo quality and pregnancy outcome in in vitro fertilization cycles. Fertil Steril 2004;82:126-131. 